\title{
Osteoporosis-pseudoglioma syndrome with congenital heart disease: a new association
}

\author{
AHMAD S TEEBI*, S A AL-AWADI*, M J MARAFIE*, R A BUSHNAQ ${ }^{*}$, \\ AND S SATYANATH \\ From * the Kuwait Medical Genetics Centre, Maternity Hospital; the Pediatric Department, Amiri Hospita \\ and $\ddagger$ the Radiology Department, Sabah Hospital, Kuwait.
}

SUMMARY We report a sibship of two brothers and one sister with the osteoporosisur pseudoglioma syndrome and congenital heart disease. They presented in infancy with visuait impairment and psychomotor retardation. Major features included bilateral cataracts, generaß ised osteopenia, severe platyspondyly, borderline mental retardation, muscular hypotonia, join? laxity, and ventricular septal defect. Parental consanguinity and affected sibs of both sexes strongly suggested autosomal recessive inheritance. Analysis of the present and previousl reported cases showed a wide range of interfamilial variability which may point to the existence of multiple allelism or genetic heterogeneity in this syndrome.

The osteoporosis-pseudoglioma syndrome is a rare genetic disorder comprising early generalised osteoporosis, visual impairment, muscular hypotonia, and joint laxity. Probably the first instance of the condition was reported in 1931 by Pellathy. ${ }^{1}$ Since then another 29 patients from 10 families have been described. ${ }^{2-14}$ Some of these families ${ }^{23}$ were later described in more detail. ${ }^{56}$ Of the 11 reported families, eight were from Mediterranean countries. We report here an Arab family with three affected sibs with the osteoporosis-pseudoglioma syndrome and congenital heart disease and some other previously unrecognised findings.

\section{Case reports}

CASE 1

The proband was a five year old disabled boy when examined in August 1985. He was referred because of visual impairment and psychomotor retardation and had a brother and a sister with the same condition. Their parents were phenotypically normal first cousins from Oman. Both were 30 years old and had an older daughter and son who were reported to be normal. No-one in the last four generations of the family had a similar problem. The proband and his affected brother and sister were all born normally at term after uneventful pregnancies with unremarkable neonatal histories, though floppiness was noticed in the first few months of life.

Received for publication 2 August 1986.

Revised version accepted for publication 17 October 1986
The proband had a visual problem suspected at the age of four months and bilateral cataracts were diagnosed and operated upon when he was si months old. Subsequently, little improvement in hi̊̈ vision was noticed but in the last two years furthe deterioration has occurred. He sat at the age of 18 months and could crawl at 20 months. However, he can not walk, can only stand with support, an moves around on his bottom because of inability te. bear his weight. Recently, he had a fractured femu after a fall from bed.

On examination he had stunted growth wit height $91 \mathrm{~cm}$, weight $10 \mathrm{~kg}$, and head circumference (OFC) $50 \mathrm{~cm}$. He had normal craniofacial featureso yellow teeth, short, collapsed spine, barrel shape chest with sternal bulge, protuberant abdomen wit? no hepatosplenomegaly, and hyperextensible joints more pronounced in the hands and feet. Muscles. were generally hypotonic with a mild degree of wasting in both upper and lower limbs but n8 limitation of movement. Neurological examinatiof showed no abnormality. IQ using the Griffith mental developmental scale was 60 . Cardiovasculag examination revealed a pansystolic murmur heard maximally at the lower sternal edge suggestive of ventricular septal defect, thought to be a large one on ECG and echocardiography. Hearing and speecto were normal. Eye examination showed blue scleraeo normal sized globes, nystagmus, bilateral catarac (needing to be reoperated), cloudy vitreoretina structures, and very poor vision.

Skeletal radiographs showed generalised severe 


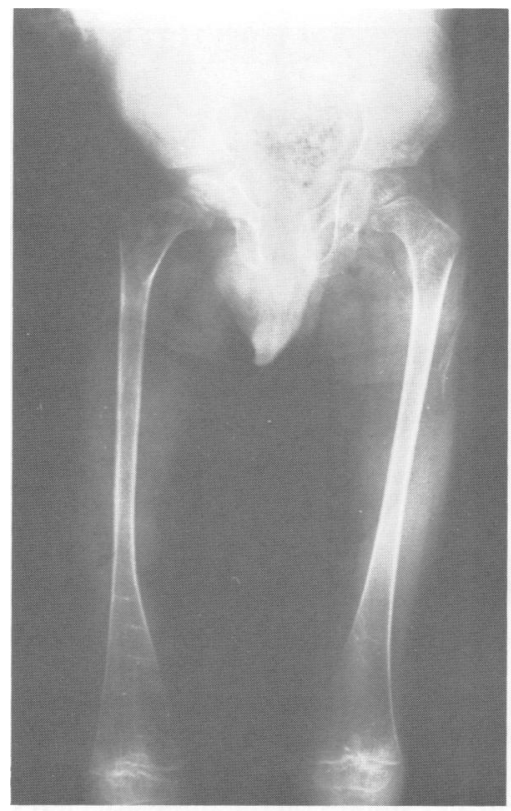

(a)

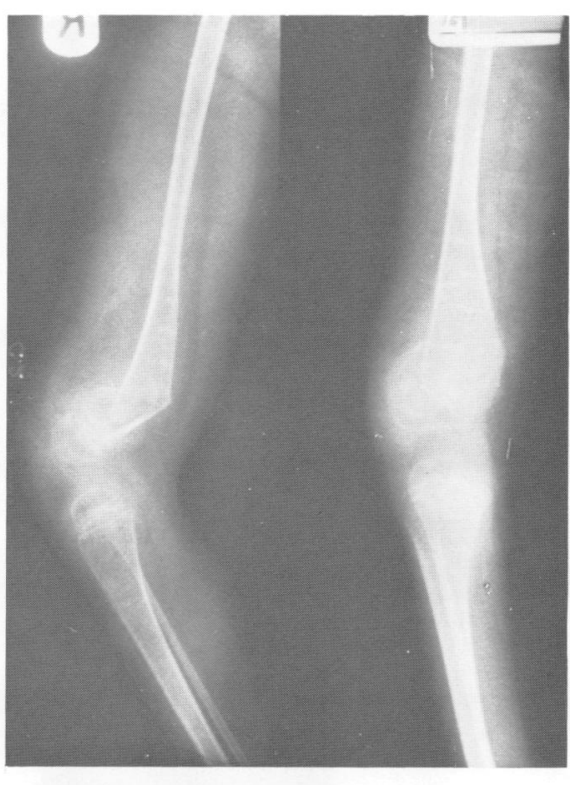

(b)

FIG 1 (a) Case 1. Radiograph showing severe osteopenia, coarse trabecular structure of both femora with thin cortex, and wide femoral necks. (b) Radiograph of the right femur showing a recent supracondylar fracture.

osteopenia, coarse trabecular structure of long bones, thin cortex, and wide femoral necks (fig 1a). The left capital humeral epiphyses showed subluxation with evidence of recent supracondylar fracture of the right femur (fig 1b). Skull bones were flattened and thin with early closure of cranial sutures and no wormian bones (fig 2). The spine showed biconcave end plates and severe platyspondyly starting in the thoracic region (fig 3). Chest $x$ ray showed cardiomegaly resulting from congenital heart disease. The bone age was normal.

Haematological and biochemical investigations showed a mild degree of iron deficiency anaemia and normal calcium, phosphorus, magnesium, and urinary excretion of calcium. Serum alkaline phosphatase was moderately raised. Creatine kinase (CK) levels and plasma and urine amino acid analysis were normal. Routine urine analysis was normal. Urine screening for reducing substances and mucopolysaccharides was negative.

CASE 2

A brother of case 1, also disabled, was examined at the age of three years. His psychomotor development was slightly delayed. He began to cruise and walk with support at the age of 18 months but he is now unable to do this and moves around on his bottom. At the age of two years, a cataract in the right eye was diagnosed and surgery performed.

On examination he showed short stature with height $85 \mathrm{~cm}$, weight $10 \mathrm{~kg}$, and $O F C 48 \mathrm{~cm}$. Features were similar to those of his brother with VSD (diagnosed clinically) but with normal coloured teeth, a slightly better muscle tone, and an IQ of 70. Eye examination also showed blue sclerae, normal sized globes, and bilateral cataract (the right eye showing recurrent cataract). Vitreoretinal structures were cloudy and vision was very poor. Skeletal radiographic findings were similar to case 1 but less severe (figs 2, 3, and 4). The same investigations as performed in case 1 showed similar findings.

CASE 3

A sister of cases 1 and 2 presented at 15 months of age. She showed slightly delayed psychomotor milestones. She sat at nine months, crawled at one year, and now can stand with support only.

On examination her height was $72 \mathrm{~cm}$, weight 8.5 $\mathrm{kg}$, and OFC $43.5 \mathrm{~cm}$. Features were similar to cases 1 and 2 with a VSD (diagnosed clinically) and an IQ of 75 to 80 . Radiological manifestations were milder (fig 3). Eye examination showed whitish sclerae, normal sized globes, and bilateral cataract with poor vision. 


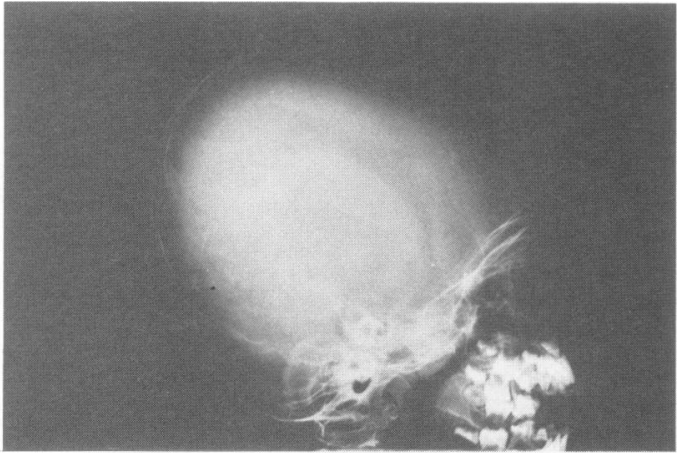

(a)

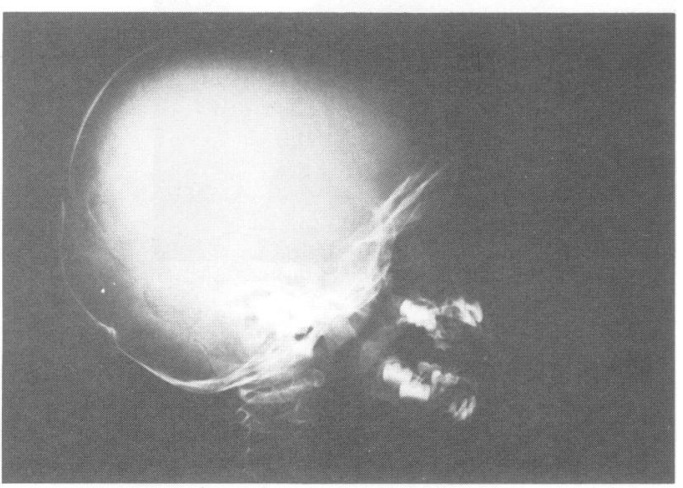

(b)

FIG 2 Skull radiographs showing thin skull bones with early closure of cranial sutures in (a) case I and (b) case 2.

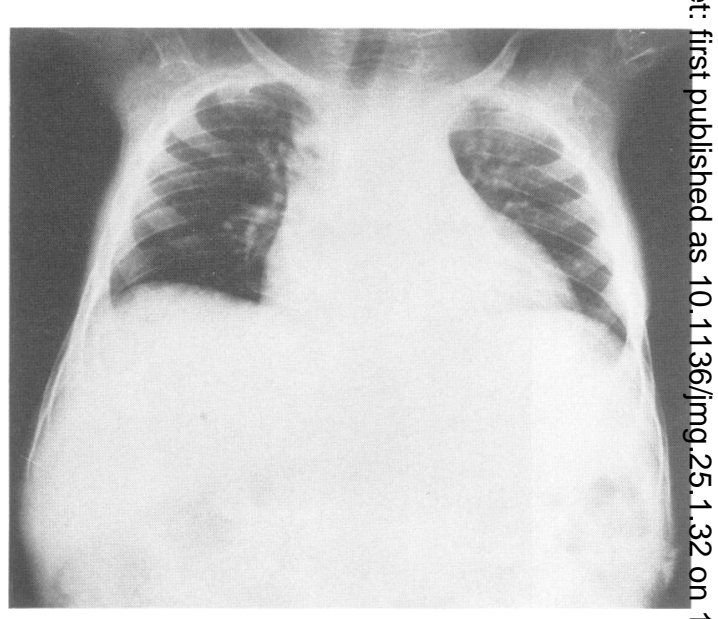

FIG 4 Case 2. Chest radiograph showing cardiomegaly.

Routine investigations showed a moderately raised alkaline phosphatase as in cases 1 and $2 . \overrightarrow{0}$

Further studies on the three affected sibs were nof possible because the family decided to return to their home country. The findings in the threes patients are summarised in the table.

\section{Discussion}

Osteoporosis-pseudoglioma syndrome (OPS) is $\overrightarrow{2}$ well delineated autosomal recessive disorder. ${ }^{15}$ As $^{3}$

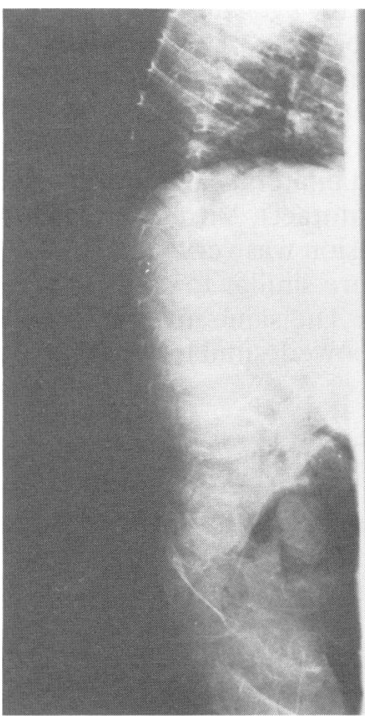

(a)

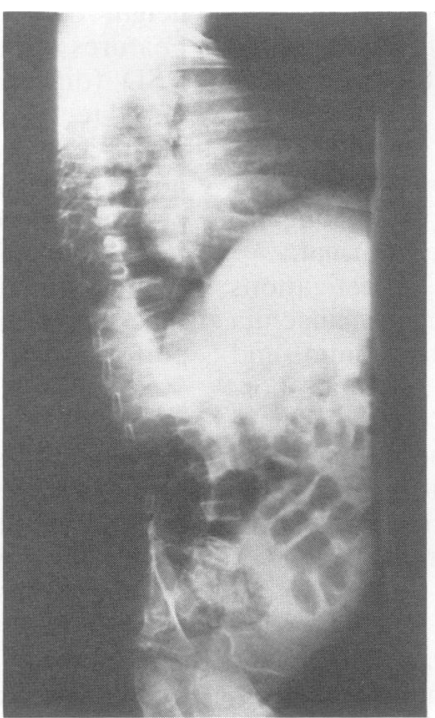

(b)

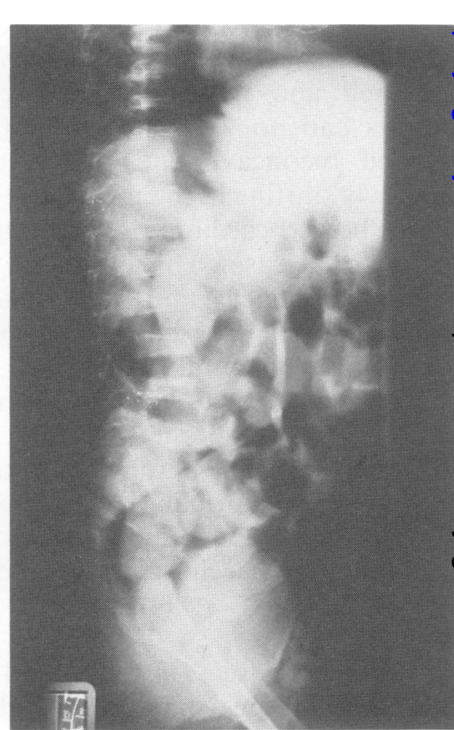

(c)

FIG 3 Lateral spine radiographs showing severe progressive osteopenia, platyspondyly, and biconcave end plates in (a) case 1, (b) case 2, and (c) case 3.

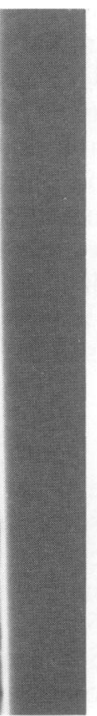


TABLE Findings in the three patients affected with osteoporosis-pseudoglioma syndrome.

\begin{tabular}{llll}
\hline Findings & Case 1 & Case 2 & Case 3 \\
\hline Sex & M & M & F \\
Age (y) & 5 & 3 & $11 / 4$ \\
Eye findings & & & \\
Poor vision & ++ & ++ & + \\
Cataract & + & + & + \\
Vitreous clouding & + & + & $?$ \\
Nystagmus & + & - & - \\
Blue sclerae & + & + & - \\
Radiological findings & & & \\
Osteoporosis & ++ & + & + \\
Platyspondyly and biconcave end plates & ++ & ++ & + \\
Flattened skull bones & + & + & + \\
Early closure of cranial sutures & + & + & $?$ \\
Fractures & + & - & - \\
General findings & & & \\
Short stature & + & + & + \\
Borderline intelligence/mild MR & + & + & - \\
Microcephaly (-2 SD) & - & + & + \\
Muscular hypotonia & + & + & + \\
Hyperextensible joints & + & + & + \\
Short spine & ++ & + & + \\
Barrel shaped chest & + & + & + \\
Discoloured teeth & + & - & - \\
Alkaline phosphatase abnormality & + & + & + \\
Congenital heart disease (VSD) & + & + & + \\
\hline
\end{tabular}

the name implies, OPS has two major components: the $x$ ray evidence of osteoporosis and the 'pseudogliomatous' changes in the eyes. These two components have been considered to be the minimal diagnostic criteria for OPS. ${ }^{13}$ Minor components which are not consistently reported include short stature, mental retardation, muscular hypotonia, joint laxity, and other anomalies.

The manifestations of OPS are in general highly variable. In all reported cases, radiographs showed generalised osteopenia with decreased bone density, coarse trabecular structure, and thin cortex. These findings are of variable severity with or without fractures and deformities. Vertebral anomalies, which include variable degrees of platyspondyly, concave end plates, and kyphoscoliosis are present in most cases. Wormian bones have been reported in some cases. ${ }^{8-1012}$

Our cases have a severe degree of osteoporosis more noticeable in the oldest, with fractures but with no deformities of long bones. They also showed progressive and severe platyspondyly with biconcave end plates of a severity never reported previously in children with OPS.

Our cases showed no wormian bones but they did have early closure of the cranial sutures, a new finding in OPS patients which may explain the microcephaly in some cases. Recently ${ }^{13}$ it was suggested that microcephaly is relative rather than absolute in relation to height, but in one of our cases it seems absolute.
Eye findings in OPS are highly variable and non-specific, though visual impairment appears to be a constant manifestation. Out of 32 cases reported so far, only one case has had normal vision. ${ }^{9}$ Some cases have congenital blindness and others have blindness of later onset. The eye manifestations may include microphthalmia, anterior chamber anomalies, cataracts, vitreoretinal anomalies, or phthisis bulbi. Our patients had poor vision, cataracts, and vitreoretinal clouding but no microphthalmia. Two of our cases had blue sclerae, a previously unrecognised finding in OPS patients reported so far.

Short stature is a common manifestation in OPS patients of various ages with or without skeletal deformities. Our cases are short with a short trunk relative to the lower limbs, as has been described previously in OPS. ${ }^{49}$

Intelligence is normal in most cases and mental retardation when present is of mild to borderline degree. ${ }^{189}$ Our cases show mild to borderline mental retardation which might be attributed in part to their poor vision and lack of external stimulation.

Muscular hypotonia and joint laxity have been recorded in about half of OPS patients ${ }^{13}$ and are thus probably integral components. ${ }^{8}$

Results of blood chemistry have usually been normal except for hypercalciuria and slight hydroxyprolinuria in one patient studied. ${ }^{4}$ Increased bone resorption and depressed bone formation with normal width of osteoid tissue were also reported by the same authors. Our cases had moderately raised alkaline phosphatase levels indicating an active process in the bone which includes increased breakdown. Such a rise is also present in patients with osteoporosis resulting from osteogenesis imperfecta. ${ }^{16}$

Congenital heart disease has not been a known association of OPS. However, our three patients showed congenital closure defect (VSD) with cardiomegaly. This association may not be fortuitous and could indicate defective collagen synthesis during morphogenesis, continuing thereafter to involve the tissues of the eye, bone, muscle, and skin. In OPS, the pattern of bone disease and its progressive nature bears a resemblance to osteogenesis imperfecta.

Additional features in common between OPS and osteogenesis imperfecta in our family are the blue sclerae and raised alkaline phosphatase levels. Our cases were diagnosed initially as atypical osteogenesis imperfecta with ocular involvement, a situation similar to an Indian family recently reported from South Africa. ${ }^{12}$ This family was in fact an example of OPS. ${ }^{14} 17$ Another earlier family with multiple fractures and blindness, but with incom- 
plete ophthalmological reports, was also reported as atypical osteogenesis imperfecta. ${ }^{18}$

In OPS, the wide range of interfamilial variability and the different associations may point to multiple allelism or to genetic heterogeneity. In general, autosomal recessive inheritance seems proven ${ }^{13}{ }^{15}$; the present family, with parental consanguinity and affected sibs of both sexes, is consistent with this form of inheritance and may represent a new form of the disease.

We are grateful to $\mathrm{Mr} M$ Sheriff, FRCS, for ophthalmological assessment. We also thank Mrs Regina Ratos for typing the manuscript.

\section{References}

${ }^{1}$ Pellathy BV. Ablatio retinae und uveitis congenita bei drei Geschwistern. Z Augenheilkd 1931;73:249-54.

2 Saraux H, Frézal J, Roy C, Aron JJ, Hayat B, Lamy M. Pseudogliome et fragilité osseuse hereditaire à transmission autosomale recessive. Ann Ocul 1967;200:1241-52.

${ }^{3}$ Saraux H, Miller H, Mawas J, Mawas E, Pepin F. La dysplasie hyaloidoretinienne (pseudogliome) à heredité recessive autosomale. Ann Ocul 1969;202:1131-7.

${ }^{4}$ Bianchine JW, Murdoch JL. Juvenile osteoporosis (?) in a boy with bilateral enucleation of the eyes for pseudoglioma. In: Bergsma D, ed. Skeletal dysplasias. New York: Alan R Liss, for the National Foundation-March of Dimes. Birth Defects 1969;5(4):225-6.

5 Briard-Guillemot ML, Saraux H, Blank MF, Frézal J. Dysplasie hyaloidoretinienne avec osteoporose. Etude de deux familles. Excerpta Medica Int Cong Ser 1971;233:34A.

6 Bianchine YW, Briard-Guillemot ML, Maroteaux P, Frézal J, Harrison HE. Generalised osteoporosis with bilateral pseudoglioma - an autosomal recessive disorder of connective tissue. Report of three families and review of literature. $A m \vec{I}$ Hum Genet 1972;24:34A.

${ }^{7}$ Chrysostomidou OM. Retinohyaloid dysplasia with osteoporosiso and hypotonia: a syndrome with autosomal recessive transmis- $\frac{\mathrm{C}}{-}$ sion in a Greek family. Excerpta Medica Int Cong Ser 1973;297:69A.

* Briard ML, Frézal J. Le pseudogliome bilateral avec osteopor- $\mathbb{\mathbb { Q }}$ ose generalisée, une affection recessive autosomique. J Genet Hum 1976;24:665-74.

${ }^{9}$ Neuhauser G, Kaveggia EG, Opitz JM. Autosomal recessive $\vec{O}$ syndrome of pseudogliomatous blindness, osteoporosis and mild. mental retardation. Clin Genet 1976;9:324-32.

10 Sauvegrain J, Dufier JL, Vacher H, Chariot JC, Le Ho'ang Phuc, Haye C. Degenerescence hyaloido-retinienne aveo. osteoporose et fragilité osseuse. J Radiol 1981;62:537-43.

1 Bartsocas CS, Zeis PM, Elia M, Papadatos CJ. Syndrome of osteoporosis with pseudoglioma. Ann Genet (Paris) 1982;25:61- ज 2.

12 Beighton P, Winship I, Behari D. The ocular form of osteogenesis imperfecta: a new autosomal recessive syndrome. $N$ Clin Genet 1985;28:69-75.

${ }^{13}$ Frontali M, Stomeo C, Dallapiccola B. Osteoporosis- pseudoglioma syndrome: report of three affected sibs andc overview. Am J Med Genet 1985;22:35-47.

14 Superti-Furga A, Steinmann B, Perfumo F. Osteoporosispseudoglioma or osteogenesis imperfecta? Clin Genet 1986;29:184-5.

15 McKusick VA. Mendelian inheritance in man. 6th ed. Balti- $\vec{\bullet}$ more: Johns Hopkins University Press, 1983.

16 Sillence DO. Genetic skeletal dysplasias. In: Behram RE, Vaughan VC, eds Nelson textbook of pediatrics. 12th ed. Philadelphia: Saunders, 1983:1634-50.

17 Robinow M. Osteoporosis-pseudoglioma syndrome? Clin Genet 1985;28:359.

${ }^{18}$ Meyer H. Atypical osteogenesis imperfecta. Lobstein's disease. Arch Pediatr 1955;72:182-6.

Correspondence and requests for reprints to Dr A S $\overrightarrow{\vec{B}}$ Teebi, PO Box 36660, 24757 Raas, Kuwait. 